\title{
A UTILIZAÇÃO DAS TECNOLOGIAS DIGITAIS DE INFORMAÇÃO E COMUNICAÇÃO NAS REDES SOCIAIS PELOS UNIVERSITÁRIOS BRASILEIROS
}

\author{
Márcia Gorett Ribeiro Grossi \\ Aline Moraes Lopes \\ Patrick Medeiros de Jesus \\ Reinaldo Ríchardi Oliveira Galvão
}

\begin{abstract}
RESUMO: Este estudo procurou verificar a utilização das redes sociais pelos universitários brasileiros, considerados pertencentes à Geração Internet (Gl), bem como traçar o perfil desta geração quanto ao uso das Tecnologias Digitais da Informação e da Comunicação (TDICs). Assim, foi realizada uma pesquisa descritiva, utilizando a técnica de coleta de dados através de um sistema informatizado pela web. Participaram da pesquisa 928 alunos de diferentes cursos de graduação de todo Brasil, contemplando as grandes áreas do conhecimento. $\mathrm{O}$ instrumento usado foi um questionário investigativo, com um link codificado para a pesquisa enviado diretamente aos e-mails dos alunos. Os resultados revelam que as redes sociais são o modus operandi da Gl. A maior parte desses indivíduos utiliza pelo menos duas redes sociais e com uma frequência diária de atividades acadêmicas, de lazer e para o trabalho. Estar conectado é uma condição essencial para a Geração Internet. A participação em questões políticas e engajamento cívico e social dos pertencentes a esta geração no Brasil é ainda pequena, quando comparada às possibilidades oferecidas pelas TDICs presentes nas redes sociais.
\end{abstract}

PALAVRAS-CHAVE: Geração Internet. Redes Sociais. Tecnológica Digital da Informação e Comunicação. Universitários Brasileiros.

\section{Introdução}

Uma geração é determinada pelo conjunto de indivíduos nascidos em uma mesma época e que possuem características comuns no que concerne a comportamentos, valores e princípios. De acordo com a Literatura, existem seis descrições de gerações: Seniors, Builderpel, Baby Boomers, Geração X, Geração Z e a Geração Y (Geração Internet, ou ainda Gl). Neste trabalho, foi contemplado o estudo desta última geração, que segundo Grossi et al (2014):

Centro Federal de Educação Tecnológica de Minas Gerais, Belo Horizonte,Brasil. Imeio: marciagrossi@terra.com.br

Centro Federal de Educação Tecnológica de Minas Gerais, Belo Horizonte,Brasil. Imeio: adrenalineletras@hotmail.com

Centro Federal de Educação Tecnológica de Minas Gerais, Belo Horizonte,Brasil. Imeio: patrickmed07@yahoo.com.br

Centro Federal de Educação Tecnológica de Minas Gerais, Belo Horizonte,Brasil. Imeio: reinaldogalvao@gmail.com

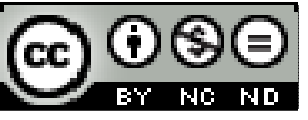

Esta obra foi licenciada com uma Licença Creative Commons

Texto Digital, Florianópolis, v. 10, n. 1, p. 4-23, jan./jul. 2014. ISSNe: 1807-9288 
é composta pelos indivíduos nascidos a partir da segunda metade da década de 1980 até a atualidade. Essa geração é marcada pelo uso intenso das tecnologias, principalmente a internet. Sua forma de pensar e agir estão pautados na agilidade, possuem destrezas em realizar várias atividades simultâneas e um desprendimento geográfico, pois suas tarefas são associadas à rede internacional de computadores. Todavia o escopo dessa geração está sendo ampliado e reforçado pelos adeptos e entusiastas das novas tecnologias. De donas de casa a empresários, a Geração GI vê cada vez mais seu espaço sendo dividido com pessoas de outras gerações que descobrem que a praticidade e a velocidade que a nuvem virtual proporciona aos que se adere a tal prática como a Geração Z. Assim, essa mescla de gerações compartilhando as mesmas formas de interatividade num espaço que até então era quase predominantemente utilizado por jovens pode ser vislumbrado positivamente na amplitude e facilidade da rede em atingir diferentes atores sociais para um objetivo comum. (GROSSI et al, 2014, p. 41)

Os jovens da Geração Internet, cuja idade varia entre 11 e 35 anos, nasceram cercados pelas TDICs, cresceram em meio à revolução das comunicações e se adaptaram a tudo isso com uma naturalidade impressionante. São, portanto, conhecidos como nativos digitais, classe que surgiu seguinte aos imigrantes digitais, termos estes que definem aqueles que nasceram antes da internet e aqueles que não imaginam o mundo sem ela (PRENSKY, 2001).

Atualmente, os integrantes da Gl estão procurando novas habilidades, cursando o ensino superior, buscando diferentes conteúdos e buscando seu espaço. Diferentemente das gerações anteriores, os jovens da GI não se contentam em ficar apenas recebendo passivamente as informações; querem participar de tudo o que está acontecendo a sua volta. Na área da educação, estão contribuindo para uma mudança nas práticas pedagógicas baseadas na colaboração entre professores e alunos. São inquietos, ávidos pela informação e pela comprovação das teorias estudadas. Nas palavras de Carvalho (2011):

temos, então, um jovem impaciente, que deseja saber, com freqüência, a avaliação do que fazem de suas ações. Isso, com certeza, afeta o desempenho da Geração Y no ambiente de trabalho, onde ela encontra gestores que se desenvolveram sem receber feedback e, portanto, nem sempre estão dispostos a dá-lo, pois acreditam que o jovem não precisa disso para trabalhar bem. (CARVALHO, 2011, p. 32) 
Os integrantes da Gl cresceram em um ambiente favorecido e enriquecido digitalmente e estão prontos para poder responder, conversar e interagir. Querem que sua educação seja relevante ao mundo no qual vivem e estão inseridos. Para eles, o que importa não é o que se sabe, mas o que se pode aprender (TAPSCOTT, 2010).

Em meio a toda essa necessidade de expandir suas habilidades ao máximo, os jovens da Gl aproveitam todas as oportunidades que o ritmo de desenvolvimento frenético da tecnologia apresenta. Como exemplo, as redes sociais que trazem uma nova forma de organização da sociedade, que é ao mesmo tempo virtual e atual, dando a possibilidade de se criar vínculos sem limites geográficos e atemporais, enquanto libera o indivíduo para criar seu próprio conteúdo e difundir suas ideias através de seus laços eletrônicos de amizade com uma facilidade e velocidade incríveis.

É inevitável pensar na Gl sem utilizar e explorar as ferramentas tecnológicas e as oportunidades e as facilidades que as redes sociais trazem para o seu mundo, seja em questões pessoais, de lazer ou de trabalho. As redes sociais exercem um papel fundamental ao dar espaço para as ideias dos seus usuários, conectandoos ao mundo todo a qualquer hora e de qualquer lugar, tornando o mundo interativo. Por meio da internet e das redes sociais, os membros da Gl conseguem expor seus pensamentos e opiniões ao mesmo tempo em que acompanham o que está acontecendo com as pessoas que fazem parte de suas redes.

Diante de tais pressupostos, o objetivo deste artigo foi verificar a utilização das redes sociais pelos universitários brasileiros, considerados pertencentes à Geração Internet, bem como traçar o perfil dessa geração quanto ao uso dessas tecnologias.

\section{Referencial teórico}




\section{1 $O$ perfil da Geração Internet}

As rápidas e impactantes transformações propiciadas pelo uso das TDICs produzem novas formas de interação e organização social, política e econômica, atuando e definindo de maneira determinante as configurações de organização e comunicação de diferentes grupos sociais, em especial entre os jovens em abrangência global.

Os grupos sociais são definidos por pertencerem a um conjunto exclusivo de eventos e fenômenos que determinam a sua singularidade na história e moldam as suas perspectivas e experiências sociais em seu contexto. Atualmente, a informação é o foco das tecnologias. Nesse cenário, a edificação de uma nova cultura e formas de agir e pensar já estão expostas e tornam-se cada vez mais evidentes entre os jovens.

Segundo Tapscott (2010), a cada dia torna-se mais evidente que a mudança mais significativa que afetou a juventude foi a ascensão do computador, da internet e de outras tecnologias digitais. Assim, é perceptível que o conjunto dessas transformações vivenciadas por esses jovens faça com que eles possuam oito características definidas pelo autor como: liberdade, customização, escrutínio, integridade, colaboração, entretenimento, velocidade e inovação.

Essas características baseiam-se nas diferentes experiências da juventude de hoje, sobretudo no que se refere ao seu consumo de mídia. Eles cresceram sendo atores, iniciadores, criadores, jogadores e colaboradores dessas mídias e estão mudando tudo, de empresas ao governo, e estar conectados é condição essencial para eles.

Portanto, os jovens de hoje, conhecidos como a Geração Internet, estão inseridos em um contexto no qual a informação é distribuída em variadas mídias, em tempo real, de fácil acesso e disponíveis em praticamente todos os lugares. Esses jovens, principalmente com a presença das diversas tecnologias digitais, estão 
desenvolvendo e impondo sua cultura a todos, reformulando a maneira como a sociedade e os indivíduos se interagem, como explica Tapscott (2010).

Ainda segundo Tapscott (2010), essa geração é muitas vezes denominada pelo senso comum como Geração Eu por estar pautada na ascensão do individualismo provocado pelas transformações e mudanças sociais e não com o uso da tecnologia em si. Essa individualidade já era percebida por Marcuse (1999) ao afirmar que:

\begin{abstract}
no decorrer do processo tecnológico, uma nova racionalidade e novos padrões de individualidade se disseminaram na sociedade, diferentes e até então mesmo opostos àqueles que iniciaram a marcha da tecnologia. Essas mudanças não são de efeito (direto ou derivado) da maquinaria sobre os seus usuários ou da produção de massa sobre os seus consumidores; são antes, elas próprias, fatores determinantes no desenvolvimento da maquinaria e da produção de massa. (MARCUSE, 1999, p. 74)
\end{abstract}

2.2 Geração Internet, ciberespaço e inteligência coletiva

O advento do desenvolvimento das TDICs propicia a propagação de informações rápidas, principalmente por meio da utilização da internet. Neste cenário, além desse acesso facilitado, há também a possibilidade de intervenção e participação dos pertencentes à Geração Internet sobre os conteúdos que estão sendo expostos, permitindo com isso uma democratização do processo de criação e difusão pública do saber.

De acordo com Lévy (2001), as atividades de pesquisa, de aprendizagem e de lazer serão virtuais ou comandadas pela economia virtual. O ciberespaço será o epicentro do mercado, o lugar da criação e da aquisição de conhecimentos, o principal meio da comunicação e da vida social, que é definido por Lévy (2000, p. 92) como sendo um "espaço de comunicação aberto pela interconexão mundial dos computadores e das memórias dos computadores." Para esse autor, a definição de ciberespaço:

inclui o conjunto dos sistemas de comunicação eletrônicos (aí incluídos os conjuntos de rede hertzianas e telefônicas clássicas), na medida em 
que transmitem informações provenientes de fontes digitais ou destinadas à digitalização. Insisto na codificação digital, pois ela condiciona o caráter plástico, fluido, calculável com precisão e tratável em tempo real, hipertextual, interativo e, resumindo, virtual da informação que é, parece-me, a marca distintiva do ciberespaço. Esse novo meio tem a vocação de colocar em sinergia e interfacear todos os dispositivos de criação de informação, de gravação, de comunicação e de simulação. A perspectiva da digitalização geral das informações provavelmente tornará o ciberespaço o principal canal de comunicação e suporte de memória da humanidade a partir do próximo século. (LÉVY, 2000, p. 92-93)

Nesse contexto, percebe-se que os jovens da Geração Internet que estão inseridos nesse ciberespaço utilizam os recursos interativos disponibilizados a partir do surgimento da internet, efetuando uma relação comunicativa mais horizontalizada chamada por Lévy (2007) de "todos-todos", caracterizada por possibilitar a interação plena de informações e conhecimentos entre todos os usuários conectados na rede. Essa disposição "todos-todos" promove a interação mútua entre os usuários através de uma flexibilização tempo-espacial aproximando pessoas de todo o mundo.

Nesse processo comunicativo, todos os usuários são centros ativos de produção coletiva de conhecimentos a serem compartilhados no ciberespaço, todavia não existe uma delimitação nítida do espaço e do tempo em que esse processo está se edificando. Portanto, todos os sujeitos devidamente conectados tornam-se difusores de conhecimentos, informações, saberes.

Esse processo é denominado por Lévy (2007) de inteligência coletiva. Assim, conforme o autor, a inteligência coletiva é a experiência da atividade plena dos usuários, que criam de forma interativa os conteúdos da rede. É uma inteligência distribuída por toda parte, incessantemente valorizada, coordenada em tempo real, que resulta em uma mobilização efetiva das competências (LÉVY, 2007).

A finalidade principal da inteligência coletiva consiste em propagar os recursos das grandes coletividades à disposição de todos os indivíduos que acessam a rede, propiciando inúmeras possibilidades como: democratização do acesso ao 
conhecimento, divulgação de movimentos sociais, engajamento cívico e inclusão social por meio, inclusive, das redes sociais.

Nessa perspectiva, pode-se então construir o conhecimento coletivo a partir da utilização de comunidades virtuais representadas pelas redes sociais como 0 Facebook. Portanto, uma comunidade virtual tem vocação para tornar-se uma inteligência coletiva (LEMOS; LÉVY, 2010).

\subsection{As redes sociais}

Foi nos primeiros anos do século XXI que o mundo pôde observar o surgimento de uma nova forma de comunicação multidirecional que se baseia na colaboração e na construção coletiva, a web 2.0 (O'REILLY, 2005). Em poucos anos, inserida neste novo modelo da web, surgem as redes sociais para consolidar a sua estrutura colaborativa e participativa.

$\mathrm{Na}$ sociedade atual, denominada de sociedade da informação e do conhecimento, a informação ganha uma valor imaginável, bem como seu acesso, disseminação e compartilhamento, e as pessoas buscam, cada vez mais, novas formas de estarem conectadas e interligadas, como explica Roque (2010):

\footnotetext{
os indivíduos buscam cada vez mais, uma constante atualização dos seus conhecimentos, emergindo assim, as redes de conhecimento (grifo do autor) que promovem por meio do estabelecimento de conexões e da interação entre os atores, uma troca intensa de informações que são convertidas em conhecimento. (ROQUE, 2010, p. 36)
}

Assim, essas redes de conhecimento vêm se modificando nessa sociedade da informação, caracterizando-se pelo compartilhamento em tempo real de um grande número de informações e firmam-se como um espaço social, alterando as formas de como as pessoas se relacionam umas com as outras.

Nas redes sociais, o usuário, além de se conectar com amigos, familiares ou até mesmo desconhecidos, também pode compartilhar qualquer conteúdo que seja, em sua opinião, relevante. Esse processo de compartilhamento permite que um 
conteúdo produzido por um usuário possa alcançar um número cada vez maior de outros usuários das redes sociais. Esse fenômeno ficou conhecido como efeito viral, de acordo com Kist (2009) e Felinto (2008).

Assim, nas redes sociais, os indivíduos podem trocar informações, experiências, criar comunidades virtuais ou fóruns de discussão que tratam de temas específicos, bem como divulgar ideias ou conceitos que acreditam ser importantes para si e para as comunidades nas quais estão inseridos.

Para Castells (2003), as redes sociais têm um papel importante na formação das novas interações sociais virtuais, ou comunidades virtuais. Desse modo:

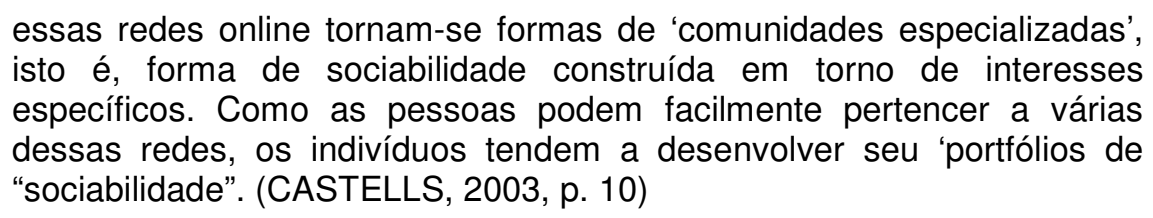

As redes sociais também têm ampliado os contatos sociais em uma posição geográfica mais abrangente e levam os indivíduos a uma manutenção mais constante desses contatos. Como lembra Castells (2003):

os usuários da internet tendiam mais do que não-usuários a se encontrar com amigos e a ter uma vida social longe de casa, embora suas redes de interação social fossem mais dispersas espacialmente que as dos não-usuários. (CASTELLS, 2003, p. 99)

Portanto, as redes sociais têm um papel fundamental na rotina da Geração Internet e têm favorecido à efetivação da sociedade virtual, rompendo fronteiras geográficas e mostrando o forte papel da individualidade na rede.

É importante ressaltar que o número de usuários ativos nas redes sociais tem crescido cada vez mais. De acordo com dados do Instituto Brasileiro de Opinião Pública e Estatística (IBOPE) ${ }^{1}$, Nielsen Online, unidade do Grupo IBOPE que promove pesquisa sobre internet no Brasil e na América Latina, em julho de 2012 ,

\footnotetext{
${ }^{1}$ Disponível em: <http://www.ibope.com.br/pt-br/noticias/paginas/cresce-o-numero-de-usuariosativos-nas-redes-sociais.aspx>. Acesso em: 08 jan. 2013.
} 
um total de 40,3 milhões de pessoas acessaram sites como Facebook e Twitter, blogs, fóruns e outras páginas de relacionamento. $O$ estudo complementa que 0 número representa um aumento de 5,7\% na comparação com o mesmo período de 2011. Portanto, o acesso às redes sociais é uma realidade no cotidiano dos brasileiros que tem mudado a maneira de interagir principalmente no que se refere a lugar, espaço e forma de compartilhamento de informações.

\section{Metodologia}

Para alcançar o objetivo deste estudo, foi realizada uma pesquisa descritiva durante os anos de 2012 e 2013, utilizando a técnica de coleta de dados através de um sistema informatizado pela web, cujo universo se restringiu às Universidades Federais, às Instituições Tecnológicas Federais Brasileiras e aos Centros Federais de Educação Tecnológica, abrangendo as cinco regiões geográficas brasileiras. Para garantir que os pesquisados fizessem parte da Geração Internet, a pesquisa foi realizada com os alunos matriculados nos anos de 2010 a 2012 e, em alguns poucos casos excluídos, os alunos acima de 35 anos.

O instrumento utilizado foi a aplicação de um questionário, acessado a partir de um link codificado para a pesquisa enviado diretamente aos e-mails dos alunos, que foram fornecidos pelas coordenações dos cursos contatados. Para escolher quais cursos iriam fazer parte da pesquisa, dois cursos foram escolhidos em cada região geográfica do Brasil: Norte, Nordeste, Centro-oeste, Sudeste e Sul, pertencentes às nove grandes áreas do conhecimento, de acordo com classificação do Conselho Nacional de Desenvolvimento Científico e Tecnológico (CNPq): Ciências Exatas e da Terra; Ciências Biológicas; Engenharias; Ciências da Saúde; Ciências Agrárias; Ciências Sociais Aplicadas; Ciências Humanas; Linguística, Letras, Artes e Outros.

Desta forma, foram enviados 7.408 e-mails, obtendo respostas de 928 universitários, sendo que, dentre as nove grandes áreas do conhecimento, 
tivemos respostas de cursos pertencentes a seis destas áreas: Ciências Exatas e da Terra; Engenharias; Ciências da Saúde; Ciências Sociais Aplicadas; Ciências Humanas e Linguística Letras e Artes, sendo os cursos: Química, Pedagogia, Medicina, Letras (Inglês e Espanhol), História, Matemática, Engenharia Elétrica, Engenharia Mecânica, Engenharia da Computação, Engenharia Civil, Engenharia Ambiental, Educação Física, Economia, Direito, Ciência da Computação e Administração.

\section{Resultados e Análises}

A descrição das características dos participantes da pesquisa foi realizada através da análise univariada, ou seja, somente uma variável, a partir das informações contidas nos questionários. Com essas informações, foi possível determinar o perfil geral dos participantes da pesquisa. Em relação ao sexo dos respondentes, a maioria dos pesquisados $540(58,19 \%)$ foi do sexo masculino e $382(41,16 \%)$ do sexo feminino. Destaca-se que seis questionários não apresentaram essa resposta.

Em relação à faixa etária dos alunos, a tabela 1 descreve distribuição da idade por faixa etária:

\begin{tabular}{c|c|c}
\hline FAIXA ETÁRIA & FREQUÊNCIA & PORCENTAGEM \\
\hline De 17 a 20 anos & 386 & 41,60 \\
\hline De 21 a 25 anos & 363 & 39,11 \\
\hline De 26 a 30 anos & 95 & 10,24 \\
\hline De 31 a 35 anos & 84 & 9,05 \\
\hline Total & $\mathbf{9 2 8}$ & $\mathbf{1 0 0 , 0}$ \\
\hline
\end{tabular}

Tabela 1 - Faixa etária dos respondentes

Observou-se que a maioria dos respondentes está na faixa de 17 a 20 anos $(41,60 \%)$ e 21 a 25 anos $(39,11 \%)$, representando $80,71 \%$ dos participantes da pesquisa, como era de se esperar. À medida que a idade avança, diminui a porcentagem dos respondentes. Não houve ausência de respostas nesta questão. 
A Tabela 2 apresentada a seguir aponta a distribuição dos cursos dos participantes da pesquisa:

\begin{tabular}{c|c|c}
\hline CURSO & FREQUENCIA & PORCENTAGEM \\
\hline Letras (Inglês / Espanhol) & 89 & 9,59 \\
\hline Engenharia Civil & 80 & 8,62 \\
\hline Administração & 75 & 8,08 \\
\hline Direito & 75 & 8,08 \\
\hline Ciência da Computação & 67 & 7,22 \\
\hline Pedagogia & 64 & 6,89 \\
\hline Engenharia Elétrica & 63 & 6,79 \\
\hline Matemática & 60 & 6,46 \\
\hline Engenharia Mecânica & 54 & 5,81 \\
\hline Engenharia da Computação & 50 & 5,34 \\
\hline Engenharia Ambiental & 36 & 3,88 \\
\hline Educação Física & 33 & 3,55 \\
\hline Ciência da Computação & 28 & 3,01 \\
\hline História & 21 & 2,26 \\
\hline Economia & 17 & 1,83 \\
\hline Medicina & 10 & 1,07 \\
\hline Química & 7 & 0,75 \\
\hline Total & 99 & 10,66 \\
\hline Não informado ou outros & 928 & $\mathbf{1 0 0 , 0}$ \\
\hline
\end{tabular}

Tabela 2 - Distribuição dos respondentes por curso

Ao analisar os dados da Tabela 2, constatou-se que os dados estão distribuídos homogeneamente, sendo que dos 928 respondentes, 9,59\% representam a área de Letras, 8,62\% a área de Engenharia Civil e 8,08\% pertencia às áreas de Administração e Direito. Os cursos que tiveram menor representatividade na pesquisa foram os cursos de Economia (1,83\%), Medicina (1,07\%) e Química com 0,75\%. Em 99 questionários respondidos (10,66\%), não estava indicado o nome do curso ou não foi possível determiná-lo por meio do método da coleta.

Em relação à análise das questões que se referem às TDICs, percebe-se que a Gl confirma a internet como uma ferramenta pertencente a estas tecnologias digitais e a eleva como centro das TDICs na atualidade. É a ferramenta mais utilizada, pois $90 \%$ a acessam diariamente. Verificou-se também que seu uso é em larga escala para estudo e lazer, sendo adotado para esses fins por $95 \%$ dos entrevistados. Esse já era um resultado esperado, uma vez que o foco desta 
pesquisa foi os estudantes do ensino superior. Outro aspecto que obteve destaque na pesquisa foi o lazer, sendo citado por $88 \%$ destes.

Não menos importante, mas totalmente calcada na existência da grande rede, estão as redes sociais com $97 \%$ de adeptos. Tendência essa já afirmada por Castells (2001): a internet foi apropriada pela prática social em toda a sua diversidade, embora essa apropriação tenha efeitos específicos sobre a própria prática social.

Os dados coletados sugerem que as redes sociais são o modus operandi da GI. A maior parte desses indivíduos possui pelo menos duas redes sociais, que são acessadas com uma frequência diária de atividades. De acordo com o relatório do Comitê Gestor da Internet no Brasil (CGI-BR) de 2012, essa frequência tende a aumentar vertiginosamente devido ao crescimento da utilização de dispositivos móveis no acesso à internet e consequentemente às redes sociais. A tabela 3 apresenta a frequência de acesso às redes sociais:

\begin{tabular}{l|c|c}
\hline \multicolumn{1}{c|}{ FREQUÉNCIA DE ACESSO ÁS REDES SOCIAIS } & RESPOSTAS & PORCENTAGEM \\
\hline Está constantemente conectado & 190 & 20,47 \\
\hline Diariamente & 458 & 49,35 \\
\hline Mais de 3 vezes por semana & 116 & 12,50 \\
\hline Semanalmente & 52 & 5,60 \\
\hline Esporadicamente & 82 & 8,84 \\
\hline Não respondido & 30 & 3,23 \\
\hline
\end{tabular}

Tabela 3 - Frequência de acesso às redes sociais

Na pesquisa percebeu-se que 57\% (532 entrevistados) dos alunos têm utilizado as redes sociais como extensão da sala de aula para interagir com os colegas, com os professores ou para busca de conteúdos, como explicitado na Tabela 4.

Através de uma análise multivariada, na qual o respondente poderia escolher mais de uma opção, verificamos que o Facebook (868 entrevistados, 93,53\%), Twitter (300 entrevistados, 32,33\%) e Orkut (284 entrevistados, 30,60\%) aparecem entre as redes sociais mais utilizadas pelos participantes da pesquisa. O Facebook é a rede social preferida desses jovens tanto para fins pessoais como profissionais. É a forma mais utilizada para relacionamentos virtuais e 
interação por meio de compartilhamentos de informações, fotos, vídeos e links, dentre outros. Em seguida, aparece o Twitter e em terceiro lugar o Orkut. Também apareceram nas respostas, mas com uma porcentagem de uso menor, mas ainda sim expressiva, o Google+, o Linkedin e o Myspace, conforme Tabela 4.

\begin{tabular}{l|c|c}
\hline \multicolumn{1}{c|}{ UTILIZAÇÃO DAS REDES SOCIAIS } & RESPOSTAS & PORCENTAGEM \\
\hline Facebook & 868 & 93,53 \\
\hline Twitter & 300 & 32,33 \\
\hline Orkut & 284 & 30,60 \\
\hline Google+ & 240 & 25,86 \\
\hline Linkedln & 184 & 19,83 \\
\hline MySpace & 18 & 1,94 \\
\hline
\end{tabular}

Tabela 4 - Redes Sociais mais Utilizadas

O foco principal da utilização das redes sociais é a criação e manutenção de laços familiares e de amizade. Partindo do princípio de que as redes sociais rompem barreiras geográficas e temporais, essa constatação faz jus à afirmação de Castells (2001) de que a internet aumenta a sociabilidade tanto à distância quanto na comunidade local. Outro item muito frequente na utilização das redes sociais é o lazer, que pode ser traduzido na forma de jogos e brincadeiras, mas que muitas vezes são atitudes como postagem de fotos, vídeos e interações sociais entre pares e comunidades de uma forma mais descontraída ou objetivando encontros sociais e culturais.

O trabalho também é citado por quase a metade dos entrevistados. Participação em fóruns e eventos, troca de e-mails, mensagens e arquivos, acessos às comunidades, ou mesmo marketing e contatos profissionais têm um grande espaço nas redes sociais, como pode ser observado pelos dados da Tabela 5.

Esse item poderia ter uma importância maior, porque aí consta o fato de que um terço dos indivíduos participantes da pesquisa apenas estuda e ainda não trabalha. Além disso, algumas empresas proíbem utilização de redes sociais no horário de trabalho por considerá-las não produtivas, de acordo com a CGI-Br de 2012. 


\begin{tabular}{l|c|c}
\hline \multicolumn{1}{c|}{ UTILIZAÇÃO DAS REDES SOCIAIS } & RESPOSTAS & PORCENTAGEM \\
\hline Contatos com amigos e familiares & 822 & 88,58 \\
\hline Lazer & 760 & 81,90 \\
\hline Estudo & 532 & 57,32 \\
\hline Trabalho & 358 & 38,58 \\
\hline Fóruns e eventos & 328 & 35,34 \\
\hline Movimentos Sociais & 310 & 33,41 \\
\hline
\end{tabular}

Tabela 5 - Utilização das Redes Sociais

Quando questionados sobre a realização de diferentes atividades ao mesmo tempo em que utilizavam as redes sociais, $97 \%$ afirmaram possuir essa prática. O que reforça a opinião de Tapscott (2010) ao afirmar que os integrantes da Geração Internet fazem várias tarefas ao mesmo tempo e em diferentes meios, possuem uma mente flexível e muito hábil para se adaptar a diversas mídias. Esse autor completa:

que eles trocam de tarefas com mais rapidez e bloqueiam o ruído de fundo com mais eficiência do que eu. Conseguem trabalhar de forma eficaz com música tocando e novidades chegando no Facebook. Conseguem manter suas redes sociais funcionando enquanto se concentram no trabalho; inclusive parecem precisar disso para se sentir à vontade. Acho que aprenderam a viver em um mundo no qual são bombardeados por informações, o que faz com que consigam bloquear a tevê ou outras distrações enquanto se concentram na tarefa que estão executando. (TAPSCOTT, 2010, p. 134)

Sobre o uso de tecnologias em sala de aula, os alunos demonstraram que elas tornam o processo de ensino e aprendizagem mais motivador, e a aprendizagem torna-se significativa, o que comprova as ideias de Almeida (2011) sobre o uso de tecnologias como recurso metodológico:

o uso das TICs facilita o interesse dos alunos pelos conteúdos, pois estamos falando de diferentes tecnologias digitais, portanto de novas linguagens, que fazem parte do cotidiano dos alunos e das escolas. Esses estudantes já chegam com o pensamento estruturado pela forma de representação propiciada pelas novas tecnologias. Portanto, utilizálas é se aproximar das gerações que hoje estão nos bancos das escolas [...] Nesse sentido, o uso das TICs pode auxiliar muito porque, quando é desenvolvido um currículo mediatizado, é feito o registro dos processos e com essa base é possível identificar qual foi o avanço 
do aluno, quais as suas dificuldades e como intervir para ajudá-lo. (ALMEIDA, 2011, Online. Grifos nossos)

Também Tapscott (2010) corrobora com essa ideia quando afirma que:

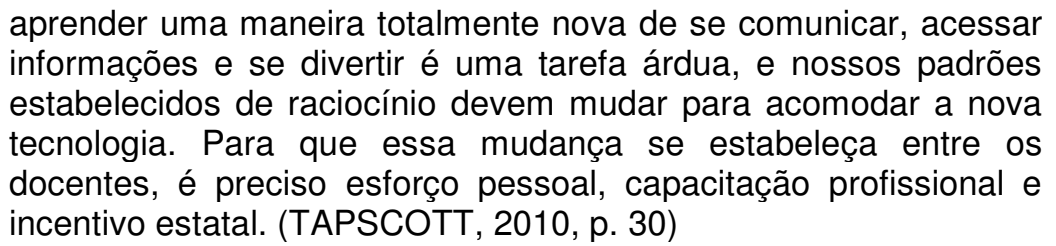

Ainda entre os resultados encontrados na pesquisa, pôde-se observar que, apesar da ampla divulgação e utilização da internet e das redes sociais, o uso dessas ferramentas está longe de provocar uma mudança significativa e abrangente nos assuntos do âmbito político e de engajamento cívico e social. Mesmo que $55 \%$ dos entrevistados tenham afirmado que participam ou apoiam algum movimento social envolvendo assuntos políticos e culturais, observou-se que essa participação é ainda passiva, pois, dentre eles, mais de $90 \%$ responderam que apenas compartilham informações prontas que chegam até eles sem a criação efetiva de conteúdos próprios que demonstrem seu pensamento e seus ideais políticos e sociais, neste caso apenas $0,43 \%$ afirmaram já ter criado conteúdo para ser distribuído.

Outro dado relevante é que $34,05 \%$ já assinaram uma petição eletrônica. $\mathrm{Na}$ Tabela 6 estão listadas todas as ações cívico/sociais realizadas através das redes sociais, pelos entrevistados:

\begin{tabular}{l|c|c}
\hline \multicolumn{1}{c|}{ AÇÕES REALIZADAS } & RESPOSTAS & PORCENTAGEM \\
\hline Compartilhei com amigos e seguidores & 462 & 49,78 \\
\hline Postei comentário & 368 & 39,66 \\
\hline Votei em enquête & 346 & 37,28 \\
\hline Assinei petição eletrônica & 316 & 34,05 \\
\hline Divulguei em blogs ou sites & 42 & 4,53 \\
\hline Criei conteúdo para ser distribuído & 4 & 0,43 \\
\hline
\end{tabular}

Tabela 6 - Ações cívico/sociais realizadas através das redes sociais

\section{Considerações Finais}


O estudo do qual nasceu este artigo revelou dados importantes com relação ao perfil e às preferências da Gl brasileira em relação às redes sociais. Através da leitura deste artigo, constata-se que a presença das TDICs na vida das pessoas trouxe diversas mudanças na forma como a informação é difundida. Essa geração já nasceu inserida em um ambiente em que a internet faz parte do cotidiano das pessoas, tornando-os conhecidos como nativos digitais.

As relações do homem com o mundo sofreram transformações que são perceptíveis nas questões políticas e sociais e no modo como se trata o meio ambiente. Mudanças tão significativas são sentidas também no ambiente escolar, na relação professor/aluno e na própria forma como a comunidade local interage com a escola. A respeito dessa reflexão Tepedino (2004) alerta que:

\begin{abstract}
estamos na era da informação e a cada dia os alunos têm mais fontes de informações ao seu alcance. Entretanto, eles precisam da ajuda dos professores para aprender a interpretar a enorme quantidade de informações que recebem. Os conteúdos se renovam constantemente e as crianças e os adolescentes conquistaram um novo espaço, também são cidadãos de um ciberespaço. Eles sabem operar os computadores melhor do que muitos adultos. Essa nova realidade requer um professor capacitado para lidar com as tecnologias e que possa assumir novos papéis na escola da Sociedade da Informação. (TEPEDINO, 2004, p. 18)
\end{abstract}

E, pela análise dos resultados, ficou clara a ampla utilização das redes sociais e das TDICs pelos universitários brasileiros que as usam como um novo espaço para estabelecer relações sociais, afetivas e como extensão da sala de aula. Esse resultado comprova a plena inserção dos jovens na realidade tecnológica e informatizada que se apresenta a eles, sendo relevante destacar a frequência com que usam essas tecnologias digitais como fator preponderante na definição do perfil do indivíduo integrante da Gl em atividades cotidianas de relacionamentos sociais, trabalho e estudo. Sobre o tema, Tapscott (2010) pontua que:

por serem as redes sociais dirigidas por jovens, são eles que estão impulsionando o renascimento de novos modelos de colaboração que sacodem as janelas e abalam as paredes de todas as instituições. (TAPSCOTT, 2010, p. 74) 
Assim, os novos hábitos dos alunos com uso das TDICs despertam interesse dos educadores e estudiosos sobre como obter benefícios ao utilizar ferramentas de redes sociais como o Facebook de forma a tê-las como aliadas aos tradicionais métodos de ensino e aprendizagem.

Os jovens da Gl querem estar envolvidos em tudo e o tempo todo, desejam absorver e compartilhar tudo aquilo que é de interesse próprio. Estão conectados com o mundo todo a partir de qualquer lugar e em qualquer hora, nos mais variados segmentos: sociais, acadêmicos, econômicos ou profissionais. Pela pesquisa, comprovou-se que essa geração apresenta a habilidade descrita por Prensky (2001) de processar mais de uma atividade por vez e realizar múltiplas tarefas, eles estão acostumados com a dinâmica e rapidez do hipertexto, com uma biblioteca disponível em seus notebooks e com a interação síncrona das mensagens instantâneas.

Nas questões sociais, Tapscott (2010) exemplifica como os jovens americanos e europeus são engajados e usam as redes sociais como aliados na divulgação e discussão de seus ideais e propósitos de uma forma rica e abrangente. No Brasil, a Gl ainda aborda as questões sociais de uma forma incipiente. Dentre os jovens entrevistados, um terço deles assinou uma petição eletrônica e uma parcela muito pequena disse já ter criado conteúdo para ser distribuído.

Portanto, os movimentos sociais ainda não fazem parte do cotidiano virtual da maioria dos alunos que responderam o questionário e quem participa deles na rede ainda tem um papel passivo. Mesmo que assuntos políticos tenham sido citados nas respostas, a passividade ficou mais uma vez evidente e os destaques ficam para os movimentos sociais de cunho cultural como festas, shows e manifestações artísticas e também de cunho ambiental, nos quais depara- se com uma grande atividade de Organizações não governamentais (ONGs) relativas a esses assuntos na rede, como nos mostra o relatório da CGI de 2012. 
Por fim, a pesquisa revela o fascínio que as redes sociais exercem sobre os estudantes pertencentes da Geração Internet por possuir diferentes tecnologias que propiciam uma comunicação fácil e rápida, além de potencializar as relações sociais, fortalecendo os laços profissionais e pessoais entre seus usuários. Conclui também que as redes sociais têm sido utilizadas como extensão das salas de aula, favorecendo a troca de conhecimento e a construção da aprendizagem devido principalmente às suas possibilidades de aprendizagem colaborativa e interativa fortemente presentes no ciberespaço, construindo o conhecimento coletivo, o que nos reporta à Levy (1996) ao afirmar que os seres humanos jamais pensam sozinhos ou sem ferramentas.

\section{THE USE OF THE DIGITAL INFORMATION AND COMMUNICATION TECHNOLOGIES BU BRAZILIAN UNIVERSITY STUDENTS}

ABSTRACT: This study aimed at verifying the use of social networks by Brazilian university students that belong to the Internet Generation (IG), as well as setting the profile of this generation concerning the use of the Digital Information and Communication Technologies (ICTs). Thus, a descriptive research, using the data collection technique via web was carried out. The sample was composed by 928 students from different graduation courses all over Brazil, including the greatest areas of knowledge. An investigative questionnaire was used, having an encoded link to the research sent to the students by e-mail. The results showed that the social networks are the modus operandi of the IG. Most of these individuals use at least two social networks with a daily frequency of some academic activities, of leisure and work. The essential condition for this Internet Generation is to be connected. The engagement of the generation in Brazil in political and civic issues as well as in socializing is still poor when compared to the possibilities offered by the ICTs present in social networks.

KEYWORDS: Internet Generation. Social Networks. Digital Information and Communication Technologies. Brazilian University Students.

\section{REFERÊNCIAS}

ALMEIDA, M. E. B. de. A tecnologia precisa estar presente na sala de aula. [Entrevista] Revista Nova escola, n. 233, Coluna Fala Mestre, jun./jul. 2010. Disponível em: avaliacao/avaliacao/ $<$ http://revistaescola.abril.com.br/planejamento-e568012.shtml?page=0 >. Acesso em: 20 mai. 2013.

CARVALHO, M. C. F. O impacto das tecnologias de informação sobre o corpo discente de instituições de ensino superior. 2011, 109 f. Dissertação (Mestrado em Engenharia de Produção), Universidade Paulista, São Paulo, 2011. 
CASTELLS, M. A galáxia da Internet. Rio de Janeiro: Jorge Zahar, 2003.

FELINTO, E. Videotrash: o youtube e a cultura do "spoof" na Internet. Revista Galáxia, São Paulo, n. 16, p.33-42, dez. 2008.

GROSSI, Márcia Gorett Ribeiro; LOPES, Aline Moraes; SILVA, Marco Polo Oliveira da; GALVÃO, Reinaldo Ríchardi Oliveira. Geração Internet, quem são e para que vieram. Um estudo de caso. Revista Iberoamericana de Ciência, Tecnologia e Sociedade, v. 9, n. 26, p. 39-54, 2014.

KIST, E. B. Flash Mobs, Movimentos que Transcendem o Ciberespaço: Uma Ferramenta Alternativa de Comunicação. 2009. Disponível em: <http://www.intercom.org.br/premios/2009/R4-1562-1.pdf>. Acesso em: 20 ago.2013.

LEMOS, André; LÉVY, Pierre. O Futuro da Internet. São Paulo: Editora Paulus, 2010.

LÉVY, Pierre. Cibercultura. São Paulo: Ed. 34, 2000.

A conexão planetária: o mercado, o ciberespaço e a consciência. Trad. de Maria Lúcia Homem e Ronaldo Entler. São Paulo: Ed. 34, 2001.

A inteligência coletiva: por uma antropologia do ciberespaço. São Paulo, Edições Loyola, 2007.

MARCUSE, Herbert. Algumas implicações sociais da tecnologia moderna. In: Tecnologia, guerra e fascismo. São Paulo: UNESP, 1999.

O'REILLY, Tim. What Is Web 2.0: Design Patterns and Business Models for the Next Generation of Software. 2005. Disponível em: <http://oreillynet.com/pub/a/oreilly/tim/news/2005/09/30/what-is-web-20.html>. Acesso em: 02 dez. 2012.

PRENSKY, M. Digital Natives, Digital Immigrants. 2001. Disponível em: <http://goo.gl/4oYb>. Acesso em: 27 dez. 2013.

ROQUE, G.O.B. Redes de conhecimento e a formação à distância. Rio de Janeiro: R. Educ. Prof., v. 36, n. 3, set/dez 2010.

TAPSCOTT, D. A hora da geração digital. Editora Agir, 2010.

TEPEDINO, S. A. S. A autoformação do professor para uso de tecnologias digitais na educação. 2004. 103 f. Dissertação (Mestrado em Educação), Pontifícia Universidade Católica de Minas Gerais, Belo Horizonte, 2004. 
Texto recebido em: 05/06/2014.

Texto aceito em: 14/07/2014. 